\title{
10-Gb/s All-Optical 2R Regeneration Using an MQW Fabry-Pérot Saturable Absorber and a Nonlinear Fiber
}

\author{
M. Pantouvaki, M. J. Fice, Member, IEEE, R. Feced, E. P. Burr, R. Gwilliam, A. B. Krysa, J. S. Roberts, and \\ A. J. Seeds, Fellow, IEEE
}

\begin{abstract}
An all-optical $2 \mathrm{R}$ regenerator that consists of an ion implanted InGaAsP multiple-quantum-well saturable absorber, a nonlinear fiber, and an optical filter is presented. Error-free $10-\mathrm{Gb} / \mathrm{s}$ transmission over $7000 \mathrm{~km}$ of standard fiber with an amplifier spacing of $80 \mathrm{~km}$ is demonstrated in a recirculating loop experiment.
\end{abstract}

Index Terms-2R regeneration, ion implantation, nonlinear optics, optical communication, optical signal processing, quantum-well devices, saturable absorbers (SAs).

\section{INTRODUCTION}

$\mathbf{O}$ PTICAL transmission in long-haul fiber systems incorporating cascaded erbium-doped fiber amplifiers (EDFAs) is limited by the accumulated amplified spontaneous emission (ASE) noise. All-optical 2R regeneration using passive saturable absorbers (SAs) is of interest as a means of reducing the noise accumulation and extending the error-free transmission distance [1].

Semiconductor SAs incorporating multiple-quantum wells (MQWs) exhibit strong nonlinear absorption response to optical power, as the photogenerated free-carrier population builds up in the MQW region, resulting in an absorption decrease when the input power increases above a threshold. Overcoming the long (nanosecond) absorption recovery time of such SAs by introducing defects in the MQW region via low-temperature molecular beam epitaxy [2], high-energy ion implantation [3], or Fe-doping [4] is required in order to make such devices usable in high bit-rate transmission systems. Improved system performance has been reported when fast SAs were incorporated at the amplification points [5], [6], while an increase in transmission distance from 1300 to $7600 \mathrm{~km}$ for a BER $<5 \times 10^{-6}$ in a $40-\mathrm{Gb} / \mathrm{s}$ system was recently demonstrated when the SA was combined with a nonlinear fiber [7]. However, application of SAs in systems with long

Manuscript received May 8, 2003; revised October 13, 2003. This work was supported in part by Nortel Networks, the European Commission, and in part by the U.K. Engineering and Physical Sciences Research Council.

M. Pantouvaki, E. P. Burr, and A. J. Seeds are with the Department of Electronic and Electrical Engineering, University College London, London WC1E 7JE, U.K. (e-mail: aseeds@ee.ucl.ac.uk).

M. J. Fice and R. Feced are with Nortel Networks, Harlow, Essex, CM17 9NA, U.K.

R. Gwilliam is with the Surrey Centre for Research in Ion Beam Applications, University of Surrey, Guildford, Surrey GU2 7RX, U.K.

A. B. Krysa and J. S. Roberts are with the EPSRC National Centre for III-V

Technologies, University of Sheffield, Sheffield S1 3JD, U.K.

Digital Object Identifier 10.1109/LPT.2003.823132

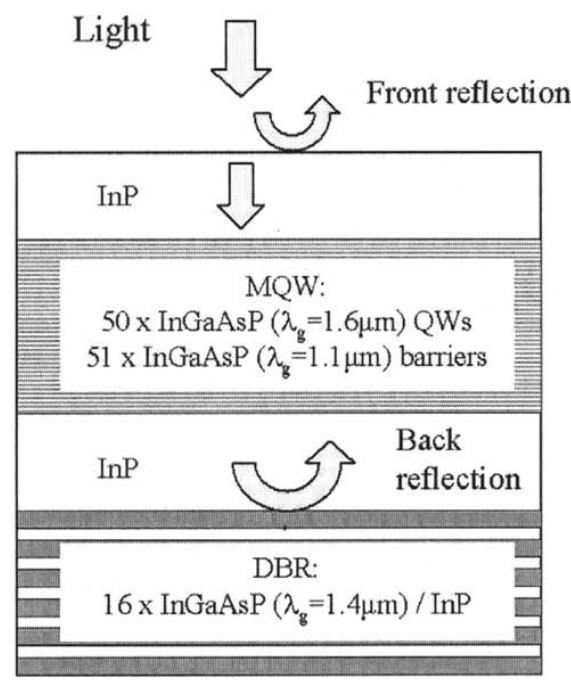

Fig. 1. Structure of the SA.

spans of standard single-mode fiber (SMF) and conventional dispersion compensation has not yet been demonstrated. For $10-\mathrm{Gb} / \mathrm{s}$ transmission systems without regeneration operating at $1550 \mathrm{~nm}$ and incorporating dispersion compensated standard fiber with $\geq 75-\mathrm{km}$ amplifier spacings, error-free transmission distances up to $\sim 2500 \mathrm{~km}$ have been demonstrated [8], [9].

Recently, we developed an MQW SA monolithically integrated in a Fabry-Pérot cavity and implanted with nitrogen ions at an energy of $4 \mathrm{MeV}$. By incorporating the SA in a $40-\mathrm{Gb} / \mathrm{s}$ system, we demonstrated ASE noise suppression on "zero" bits [10]. In this letter, we use the same device in combination with a nonlinear fiber and an optical filter to control amplitude fluctuations on "one" bits, thereby forming a $2 \mathrm{R}$ all-optical regenerator [11]. We demonstrate $10-\mathrm{Gb} / \mathrm{s}$ error-free transmission improvement to over $7000 \mathrm{~km}$ in a dispersion compensated SMF recirculating loop with an amplifier spacing of $80 \mathrm{~km}$, when the $2 \mathrm{R}$ regenerator is included in the system.

\section{EXPERIMENTAL SYSTEM}

The SA incorporates an MQW active layer formed by 50 $\operatorname{InGaAsP}\left(\lambda_{g} \approx 1.6 \mu \mathrm{m}\right)$ quantum wells, separated by InGaAsP $\left(\lambda_{g} \approx 1.1 \mu \mathrm{m}\right)$ barriers, grown by metal-organic vapor phase epitaxy (Fig. 1). To increase the contrast ratio, the device is operated in reflection and the MQW layer is integrated in an asymmetric Fabry-Pérot cavity [2], [12]. The cavity is formed by the top air-semiconductor interface and a 16-period InGaAsP 


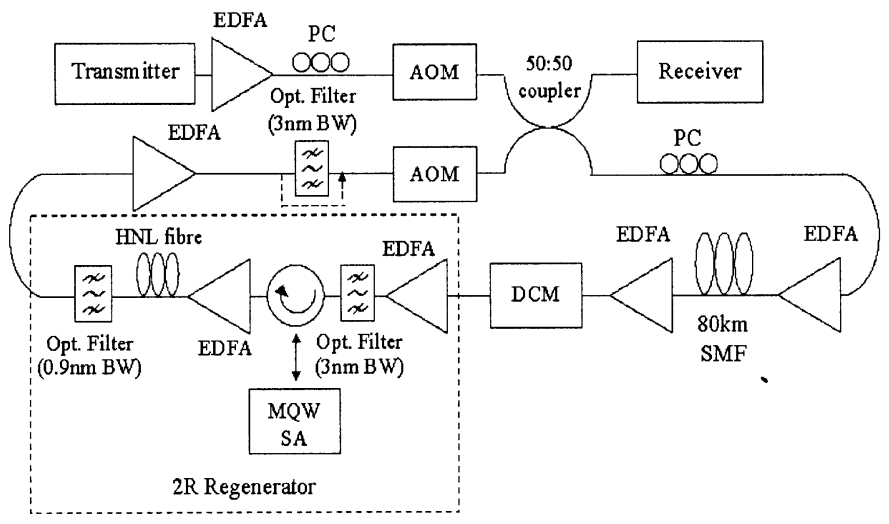

Fig. 2. Experimental configuration.

$\left(\lambda_{g} \approx 1.4 \mu \mathrm{m}\right) / \mathrm{InP}$ distributed Bragg reflector (DBR). The design of the cavity requires that the front and the effective back reflections interfere destructively at the wavelength of the MQW excitonic absorption peak, when the input power is low. To satisfy this condition, InP spacer layers are used above and below the MQW, adjusting the optical path length through the SA to induce a $\pi$-phase shift of the back reflection compared to the front reflection at the required wavelength. Under these conditions, if the input power is increased, the MQW excitonic absorption is bleached, and the back reflection becomes dominant, leading to increased overall device reflectivity. By operating at normal incidence, the device is made polarization insensitive.

To reduce the absorption recovery time of the SA, implantation of nitrogen ions was performed at $4 \mathrm{MeV}$ energy and $200{ }^{\circ} \mathrm{C}$ temperature, using a dose of $3 \times 10^{12} \mathrm{~cm}^{-2}$. At this energy, the ions pass through the MQW layer and stop in the first layers of the DBR, as calculated using the simulation program SRIM-2000 [13]. However, defects generated along the ion traces act as photocarrier trapping and recombination centers, thereby reducing the absorption recovery time, while preserving the nonlinear absorption of the MQW. A pump-probe technique using 2-ps pulses at 4-MHz repetition rate was used to measure the recovery time of the SA. The as-grown material had a $1 / \mathrm{e}$ absorption recovery time of $3 \mathrm{~ns}$, which was reduced to less than $5 \mathrm{ps}$ after implantation. Measurements of the transfer function of the SA with input pulse energy at 4-MHz repetition rate indicated a contrast ratio of $7.5 \mathrm{~dB}$ and an insertion loss of $10 \mathrm{~dB}$ (including circulator) when the SA was fully saturated, while the saturation energy of the device was estimated to be $\sim 12 \mathrm{pJ}$.

Once saturated, the SA acts as a linear loss in the system, and cannot reduce any amplitude fluctuations or noise accumulated on "one" bits. In [11], Matsumoto et al. suggested the combination of an SA with a highly nonlinear fiber and a bandpass filter, to form a $2 \mathrm{R}$ regenerator. Self-phase modulation in the fiber results in pulse-compression, and energy equalization is achieved by transmitting the pulses through an optical bandpass filter. To complete the $2 \mathrm{R}$ regenerator, a 3-km span of TrueWave RS fiber $(D \sim 4 \mathrm{ps} / \mathrm{nm} / \mathrm{km})$ was used after the SA, followed by an optical filter of 0.9-nm bandwidth.

The $2 \mathrm{R}$ regenerator was tested in a $10-\mathrm{Gb} / \mathrm{s}$ recirculating loop. The experimental configuration is shown in Fig. 2. The loop consists of $80 \mathrm{~km}$ of SMF ( $D=17 \mathrm{ps} / \mathrm{nm} / \mathrm{km})$, followed

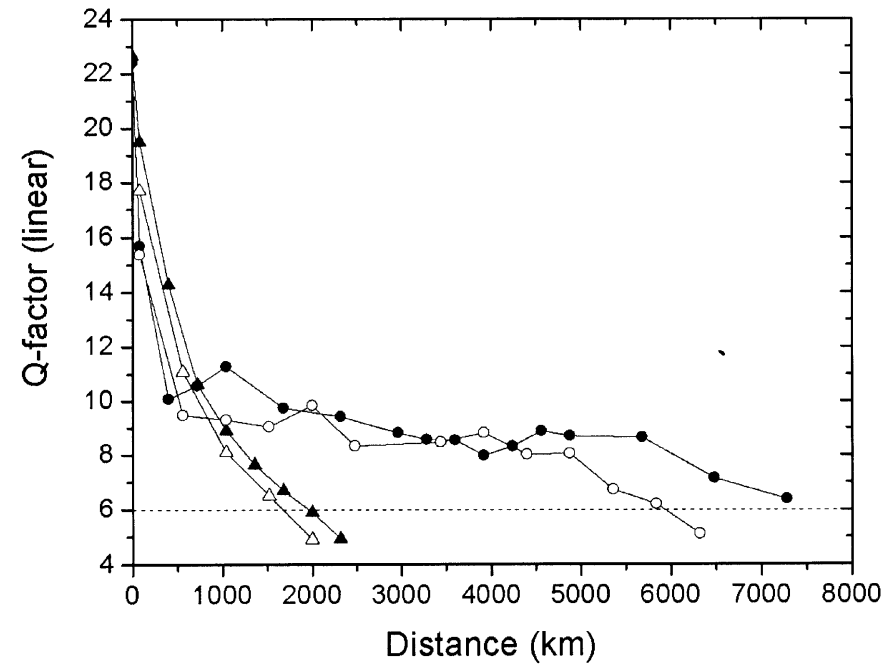

Fig. 3. Evolution of $Q$ factor (linear) without (triangles) and with (circles) the $2 \mathrm{R}$ regenerator in the system, for $2^{7}-1$ PRBS (solid symbols) and $2^{31}-1$ PRBS (open symbols).

by an EDFA and a dispersion compensation module (DCM) to compensate for the fiber loss $(0.25 \mathrm{~dB} / \mathrm{km})$ and dispersion, respectively, while two acoustooptic modulators (AOMs) provide switching through a $3-\mathrm{dB}$ coupler. The mean power at the input of the $80-\mathrm{km}$ span is set to $1 \mathrm{dBm}$. The DCM consists of dispersion compensating fiber $(\sim-1400 \mathrm{ps} / \mathrm{nm})$, trimmed using 1.4-km SMF to minimize distortion of a $40-\mathrm{Gb} / \mathrm{s}$ eye after 15 recirculations around the loop without regeneration. The input power to the DCM was $-1 \mathrm{dBm}$. The $10-\mathrm{Gb} / \mathrm{s}$ input signal consists of 6-ps (full-width at half-maximum) return-to-zero pulses at $1550 \mathrm{~nm}$, modulated with a pseudorandom binary sequence (PRBS) data sequence.

The regenerator consists of two sections: The first section incorporates an EDFA, a 3-nm bandwidth optical filter and the $\mathrm{SA}$, with $\sim 16.5-\mathrm{dBm}$ power incident on the SA. The second section incorporates an EDFA that provides $10 \mathrm{dBm}$ at the input of the nonlinear fiber, which is followed by the optical bandpass filter.

\section{RESUlTS AND DISCUSSION}

To evaluate the performance of the system without the regenerator, a 3-nm bandwidth optical filter was used before the AOM in the loop, to limit the accumulation of out-of-band ASE noise and jitter in the transmission system as the number of recirculations increases. When the regenerator was added to the system, the 3-nm bandwidth filter was bypassed, as indicated by the dashed arrow in Fig. 2. The evolution of the $Q$ factor with distance was measured with and without the regenerator in the system. Fig. 3 shows the experimental linear $Q$ factor with distance without and with regeneration in the system, for modulation with $2^{7}-1$ PRBS and $2^{31}-1$ PRBS data sequences. The maximum error-free propagation distance $(Q$ factor $>6)$ for a $2^{7}-1$ PRBS data sequence without noise suppression was $<2000 \mathrm{~km}$. Adding the $2 \mathrm{R}$ regenerator in the system, an error-free distance of $>7280 \mathrm{~km}$ was achieved. The performance of the system was also examined when the input signal was modulated with a $2^{31}-1$ PRBS. Using a longer bit sequence 


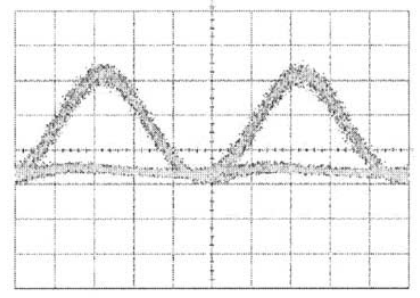

(a)

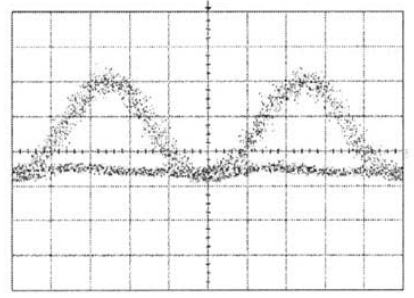

(c)

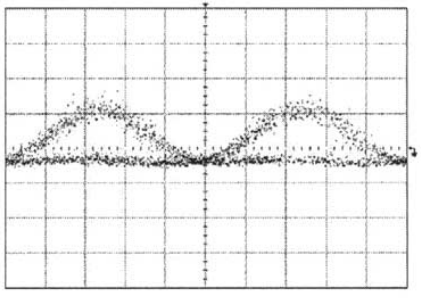

(b)

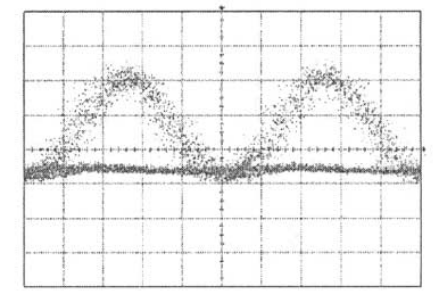

(d)
Fig. 4. Eye diagrams for $2^{7}-1$ PRBS, after electrical detection. (a) Input, (b) Without regeneration, after $2000 \mathrm{~km}$. (c) With regeneration, after $2320 \mathrm{~km}$. (d) With regeneration, after $6480 \mathrm{~km}$.

allows for longer sequences of consecutive "one" bits, which would degrade the system performance severely if the regenerator introduces strong patterning. Without the $2 \mathrm{R}$ regenerator, the $Q$ factor degrades fast and error-free transmission is only achieved over $\sim 1600 \mathrm{~km}$. When the regenerator is included in the system, the error-free transmission distance is increased to over $5840 \mathrm{~km}$. The faster degradation of the $Q$ factor in this case, compared to that for the shorter data sequence, is observed both without and with regeneration, and can be attributed to more intense jitter. It is interesting to note that for both lengths of PBRS, an improvement by a factor of $\sim 3.6$ in transmission distance was achieved.

The electrical eye diagrams of the input signal and after $\sim$ $2000 \mathrm{~km}$ without and with the regenerator in the recirculating loop are shown in Fig. 4. At 2000 km, noise accumulation causes eye closure in the case without regeneration. A clear improvement is observed with the $2 \mathrm{R}$ regenerator in the system at similar distances, while the main system limitation as the transmission distance increases to $>6480 \mathrm{~km}$ is timing jitter.

In order to explore the system enhancement through regeneration, we deliberately increased the loss per span and measured the $Q$ factor at a distance of $3440 \mathrm{~km}$. Initially, the optical signal-to-noise ratio (SNR) measured after a single span was $30.5 \mathrm{~dB}$ (resolution bandwidth of $0.1 \mathrm{~nm}$ for the noise measurement), while the $Q$ factor after 43 recirculations in the loop $(3440 \mathrm{~km})$ was 8.55 . When the loss per span was increased by $2.8 \mathrm{~dB}$, the optical SNR and $Q$ factor were reduced to $28.5 \mathrm{~dB}$ and 6.2 , respectively. The result shows that the interamplifier spacing could be increased to over $90 \mathrm{~km}$ while maintaining error-free transmission.

\section{CONCLUSION}

An ion-implanted MQW SA integrated in a Fabry-Pérot cavity was combined with a nonlinear fiber and an optical filter to form a $2 \mathrm{R}$ regenerator. The $2 \mathrm{R}$ regenerator was tested in a $10-\mathrm{Gb} / \mathrm{s}$ transmission system and an improvement by a factor $>3.5$ in the error-free transmission distance was demonstrated for $2^{7}-1$ and $2^{31}-1$ PRBS modulated signals. The MQW SA is polarization insensitive, passive, and requires no postimplant fabrication.

\section{REFERENCES}

[1] D. Atkinson, W. H. Loh, V. V. Afanasjev, A. B. Grudinin, A. J. Seeds, and D. N. Payne, "Increased amplifier spacing in a soliton system with quantum-well saturable absorbers and spectral filtering," Opt. Lett., vol. 19, no. 19, pp. 1514-1516, Oct. 1994.

[2] R. Takahashi and Y. K. Iwamura, "1.55 $\mu \mathrm{m}$ ultrafast surface-reflection all-optical switching using low-temperature-grown Be-doped strained MQWs," in Eur. Conf. Optical Communications (ECOC 1994), vol. 4, 1994, pp. 113-116.

[3] E. L. Delpon, J. L. Oudar, N. Bouché, R. Raj, A. Shen, N. Stelmakh, and J. M. Lourtioz, "Ultrafast excitonic saturable absorption in ion-implanted InGaAs/InAlAs multiple quantum wells," Appl. Phys. Lett., vol. 72, no. 7, pp. 759-761, Feb. 1998.

[4] A. Marceaux, S. Loualiche, O. Dehaese, and B. Lambert, "High-speed $1.55 \mu \mathrm{m}$ Fe-doped multiple-quantum-well saturable absorber on InP," Appl. Phys. Lett., vol. 78, no. 26, pp. 4065-4067, June 2001.

[5] Z. Bakonyi, G. Onishchukov, C. Knöll, M. Gölles, and F. Lederer, "10 Gbit/s RZ transmission over $5000 \mathrm{~km}$ with gain-clamped semiconductor optical amplifiers and saturable absorbers," Electron. Lett., vol. 36, no. 21, pp. 1790-1791, Oct. 2000.

[6] J. Mangeney, S. Barré, G. Aubin, J. L. Oudar, and O. Leclerc, "System application of $1.5 \mu \mathrm{m}$ ultrafast saturable absorber in $10 \mathrm{Gbit} / \mathrm{s}$ long-haul transmission," Electron. Lett., vol. 36, no. 20, pp. 1725-1727, Sept. 2000.

[7] D. Rouvillain, P. Brindel, F. Seguineau, L. Pierre, O. Leclerc, H. Choumane, G. Aubin, and J. L. Oudar, "Optical 2R regenerator based on passive saturable absorber for $40 \mathrm{Gbit} / \mathrm{s}$ WDM long-haul transmissions," Electron. Lett., vol. 38, no. 19, pp. 1113-1114, Sept. 2002.

[8] C. Caspar, H. M. Foisel, A. Gladisch, N. Hanik, F. Küppers, R. Ludwig, A. Mattheus, W. Pieper, B. Strebel, and H. G. Weber, "RZ versus NRZ modulation format for dispersion compensated SMF-based 10-Gb/s transmission with more than 100-km amplifier spacing," IEEE Photon. Technol. Lett., vol. 11, pp. 481-483, Apr. 1999.

[9] N. Kikuchi, S. Sasaki, and K. Sekine, "10 Gbit/s dispersion-compensated transmission over $2245 \mathrm{~km}$ conventional fibers in a recirculating loop," Electron. Lett., vol. 31, no. 5, pp. 375-377, Mar. 1995.

[10] M. Pantouvaki, E. Burr, R. Feced, M. Fice, R. Gwilliam, J. S. Roberts, and A. J. Seeds, " $40 \mathrm{~Gb} / \mathrm{s}$ optical noise suppression and wavelength conversion by MQW saturable absorber integrated in a Fabry-Pérot cavity," in Eur. Conf. Optical Communications (ECOC 2002), vol. 3, Copenhagen, Denmark, Paper 6.3.6.

[11] M. Matsumoto and O. Leclerc, "Analysis of 2R optical regenerator utilizing self-phase modulation in highly nonlinear fiber," Electron. Lett., vol. 38, no. 12, pp. 576-577, June 2002.

[12] M. Whitehead, A. Rivers, G. Parry, J. S. Roberts, and C. C. Button, "Low-voltage multiple quantum well reflection modulator with on:off ratio > 100:1," Electron. Lett., vol. 25, no. 15, pp. 984-985, July 1989.

[13] J. F. Ziegler, J. P. Biersack, and U. Littmark, The Stopping and Range of Ions in Solids. New York: Pergamon, 1985, vol. 1, The Stopping and Ranges of Ions in Matter. 